\title{
Prevalence of overweight and its associated risk factors among adolescents: A cross-sectional study in peri-urban area of Nepal
}

Elina Khatri ( $\square$ elinakhatri1992@gmail.com )

MPH Scholar, Patan Academy of Health Sciences

Rajesh Kumar Yadav

Birat Nepal Medical Trust Nepal

Sushila Baral

Provincial Health Training Center, Gandaki Province

Sudha Poudel

Nepal Health Research Council

Kedar Prasad Baral

Patan Academy of Health Sciences

\section{Research Article}

Keywords: Prevalence, Overweight, Risk Factors, Adolescents, Peri-urban, Nepal

Posted Date: September 24th, 2021

DOI: https://doi.org/10.21203/rs.3.rs-919325/v1

License: (c) (i) This work is licensed under a Creative Commons Attribution 4.0 International License. Read Full License 


\section{Abstract \\ Background}

Adolescence, being a crucial stage for experimentation and acceptance of new behavioral and lifestyle choices, is detrimental to their nutritional status. The nutritional status of adolescents being shaped by socio-cultural, environmental, and economic factors has also been impacted by their food habits and level of physical activity. The current nutritional shift and rapid urbanization had emerged overweight as an additional burden for consistently prevalent undernutrition issues. So, the study aimed to identify the prevalence of and risk factors for overweight among school adolescents.

\section{Methods}

A school-based cross-sectional analytical study was carried out among school adolescents in a Submetropolitan city of Nepal. A random sample of 279 adolescents from nine schools was included in the study. The anthropometric measurement of the height and the weight were measured as per the standard. The odds ratio with a $95 \% \mathrm{Cl}$ was calculated and a p-value of $\leq 0.05$ was considered as cut off for statistical significance by fitting into the final multivariable logistic regression.

\section{Results}

The overall prevalence of overweight was obtained as $9.31 \%(95 \% \mathrm{Cl}: 6.40-13.3)$. The mean age of respondents was 15.5 years. The early aged adolescents were more overweight than compared to middleaged adolescents (AOR: 0.27, Cl: 0.028-2.67) and late adolescents (AOR: 0.66, Cl: 0.068-6.44) respectively. Similarly, adolescents residing in rural areas had 0.35 (AOR $=0.33, \mathrm{Cl}: 0.030-3.71)$ odds of being overweight compared to their counterparts. Adolescents with sedentary behavior were 4 times $(A O R=3.51, \mathrm{Cl}: 0.79-15.54)$ more likely of being overweight than their counterparts.

\section{Conclusions}

Overweight among adolescents in urban areas has emerged as an alarming issue with the increasing burden. It is therefore pertinent to emphasize adolescents to improve healthy weight status.

\section{Background}

Overweight is the condition characterized by an abnormal and extreme accumulation of fat which can worsen bodily functions. ${ }^{1}$ It is one of the major risk factors for most chronic illness related to diet and body mass index ${ }^{2}$ and is considered a multifactorial chronic conditions that is affected by genetic, metabolic, behavioral, environmental, cultural and socioeconomic factors. ${ }^{3}$ Adolescence, being a crucial 
stage for experimentation and acceptance of new behavioral and lifestyle choices, is detrimental to their nutritional status. ${ }^{4}$ The nutritional status of adolescents being shaped by socio-cultural, environmental, and economic factors has also been impacted by their food habits and level of physical activity. ${ }^{5}$ Although obesity and overweight have become pandemic even in the developing world, it has been a most neglected problem until quite recently. ${ }^{6}$ However, the burden of overweight among adolescents has been increased in both developed and developing countries. ${ }^{5}$ Globally, overweight has nearly been tripled since 1975 with more than 340 million children and adolescents aged 5-19 years being overweight in 2016. ${ }^{1}$ Approximately 170 million adolescents i.e. children under 18 years were overweight or obese in 2008 and it has been estimated that around $30 \%$ of all children will be obese or overweight by $2030 .{ }^{7}$ Such conditions is termed as "New World Syndrome" as 40-50 million school-aged children worldwide are obese. ${ }^{3}$ According to the World Health Organization (WHO), maximum percentage of overweight children is in developing countries with a higher rate of increment as compared to the developed world. ${ }^{7}$

The current shift in lifestyle and change in consumption patterns of high energy-dense diets which are rich in fat and calorie content and low intake of micronutrients such as vitamins and minerals could be the reasons towards overweight among adolescents. In developing countries, the advancement in the accessibility of food and decrease in physical activity had been recognized as major contributing factors for increasing trend of overweight and other chronic metabolic diseases. ${ }^{8}$ In addition to this, physical activity during adolescence stage is considered to have a positive impact on physiological and psychological growth and development which is continued to adulthood. ${ }^{9}$

The prevalence and risk associated with overweight and obesity among adolescents in developing nations are increasing at a higher rate as compared to developed. ${ }^{10}$ Nearly a quarter of population in Nepal are adolescents which cover about 23.45 percent of the total population. ${ }^{11}$ The problem of overweight and obesity is also becoming public health challenge along with the consistent problem of undernutrition. ${ }^{12}$ The unavailability of data with standard cut-off values and references has made it difficult for comparisons and trend analysis of overweight among adolescents worldwide. ${ }^{8}$ This study aims to identify the prevalence of and associated risk factors of overweight among school adolescents of the sub-metropolitan city, Nepal.

\section{Methods}

The school-based cross-sectional analytical study was done among the adolescents from secondary schools of Hetauda Sub-Metropolitan City, Makwanpur district. The study participants were selected randomly based on their enrollment in either government or private schools. The sample size was computed as 272 adolescents by using a single proportion sample using the prevalence of overweight among higher secondary school adolescents as $12.2 \%{ }^{10}$ with $95 \%$ confidence interval at $5 \%$ margin of error, $10 \%$ of non-response rate and design effect as 1.5 based on a study done in Kathmandu valley. Sampling was done by using multi-stage random sampling. The updated list of secondary schools was obtained from the concerned authorities. 10\% (9 schools) were selected to meet the minimum sample 
size. Since there was a significant difference in the number of students from government and private schools proportional allocation based on the number of students enrolled in both types of schools, 6 government, and 3 private schools were selected through Probability Proportionate to Size (PPS) sampling. Finally, participants were selected in equal distribution using the Systematic Random Sampling (SRS) technique.

Data was collected using a validated and structured self-administered tool for assessing adolescents' socio-demographic characteristics, food habits, physical activity, and anthropometric measurements. An electronic SECA digital weighing scale (UNICEF Electronic Scale) was used to measure the weight of all adolescents. Height was measured by using a standard height measuring board (Shorr-Board) in a standing position by following standard procedures.

Data were coded and entered in Epi Info 7 and analyzed using STATA MP 13 software. However, the anthropometric assessment was done in WHO Anthro Plus Software V.1.0.4 to monitor the BMI status of adolescents. For descriptive analysis data were expressed in frequency, percentage, mean and standard deviation. For analytical purposes, suitable statistical test either parametric or non-parametric was performed based on the nature of data. Bivariate and multivariate logistic regression analyses were conducted to determine the association between dependent and independent variables.

\section{Results}

The socio-demographic information of school adolescents such as age, sex, place of residence, ethnicity, religion, parental education and employment status, school type, birth order, and physical environmental factors was assessed for descriptive analysis as well as understanding its association with overweight among adolescents.

Almost $56 \%$ of participants belong to middle adolescents followed by $29.39 \%$ in later adolescents with $14.70 \%$ in early adolescents group. More than half (i.e. 158 out of 279) of study participants were female i.e. $56.63 \%$ with $43.37 \%$ as male adolescents. The majority of adolescents i.e. $90 \%$ reported as urban residents with $10 \%$ residing in rural areas. Approximately $90 \%$ of adolescents were found to be residing in urban areas. Also, in this study about two-third of school adolescents (i.e.66.67\%) were from government. More than half i.e. $61.29 \%$ of school adolescents belong to the nuclear family. (Table 1) 
Table 1

Background characteristics of adolescents $(n=279)$

\begin{tabular}{|lll|}
\hline Variables & Frequency (N) & Percentage (\%) \\
\hline Age (Completed years) & & \\
\hline $11-13$ (early adolescents) & 41 & 14.70 \\
\hline $14-16$ (middle adolescents) & 156 & 55.91 \\
\hline $17-19$ (late adolescents) & 82 & 29.39 \\
\hline Sex & & \\
\hline Male & 121 & 43.37 \\
\hline Female & 158 & 56.63 \\
\hline Place of Residence & & 89.61 \\
\hline Urban & 250 & 10.39 \\
\hline Rural & 29 & \\
\hline Birth Order & & 41.94 \\
\hline First & 117 & 25.09 \\
\hline Middle & 70 & 32.97 \\
\hline Last & 92 & 33.33 \\
\hline Type of School & & \\
\hline Government & 186.67 \\
\hline Private & & \\
\hline Type of Family & & \\
\hline Nuclear & & \\
\hline Joint & & \\
\hline
\end{tabular}

The parental background characteristics of participants were included in this study to assess the relationship between these variables and overweight among adolescents. More than one-fourth i.e. $29.03 \%$ of adolescent's mothers were without any education followed by $22.22 \%$ of them educated up to secondary level and $17.92 \%$ and $17.20 \%$ educated through informal education and educated up to primary level respectively with few i.e. $9.68 \%$ educated up to higher secondary level. Similarly, $29.03 \%$ of adolescent's father was educated up to secondary level. However, $12.19 \%$ of fathers were without education. More than half i.e. $55.20 \%$ of the adolescent's mothers were found to be house makers followed by $24.37 \%$ of mothers engaged in agriculture as their occupation. (Table 2 ) 
Table 2

Parental characteristics of adolescents $(n=279)$

\begin{tabular}{|c|c|c|}
\hline Variables & Frequency $(\mathrm{N})$ & Percentage (\%) \\
\hline \multicolumn{3}{|c|}{ Mother's Education Level } \\
\hline No education & 81 & 29.03 \\
\hline Informal education & 50 & 17.92 \\
\hline Primary & 48 & 17.20 \\
\hline Secondary & 62 & 22.22 \\
\hline Higher secondary & 27 & 9.68 \\
\hline University & 11 & 3.94 \\
\hline \multicolumn{3}{|c|}{ Father's Education Level } \\
\hline No education & 34 & 12.19 \\
\hline Informal education & 37 & 13.26 \\
\hline Primary & 55 & 19.71 \\
\hline Secondary & 81 & 29.03 \\
\hline Higher secondary & 51 & 18.28 \\
\hline University & 21 & 7.53 \\
\hline \multicolumn{3}{|l|}{ Mother's Employment } \\
\hline House maker & 154 & 55.20 \\
\hline Agriculture & 68 & 24.37 \\
\hline Labor & 6 & 2.15 \\
\hline Government services & 12 & 4.30 \\
\hline Private job & 16 & 5.73 \\
\hline Business & 18 & 6.45 \\
\hline Others & 5 & 1.79 \\
\hline \multicolumn{3}{|l|}{ Father's Employment } \\
\hline Agriculture & 58 & 20.79 \\
\hline Labor & 25 & 8.96 \\
\hline Government services & 29 & 10.39 \\
\hline Private job & 46 & 16.49 \\
\hline
\end{tabular}




\begin{tabular}{|lll|}
\hline Variables & Frequency(N) & Percentage (\%) \\
\hline Business & 65 & 23.30 \\
Foreign employment & 44 & 15.77 \\
Others & 12 & 4.30 \\
\hline
\end{tabular}

The analysis of nutritional status of adolescents in terms of overweight was done based on the BMI for age z scores. All 279 sampled adolescents were measured for height and weight. The mean weight for adolescents was found to be $48.91 \mathrm{~kg}$ (95\% Cl 47.83-49.99) with minimum and maximum weight as $29.3 \mathrm{~kg}$ and $95 \mathrm{~kg}$ respectively. The reported average height of adolescents was found to be $157.37 \mathrm{~cm}$ (95\% $\mathrm{Cl} 156.43-158.31)$ with minimum and the maximum height of adolescents as $130 \mathrm{~cm}$ and 179.5 cm. (Table 3)

Table 3

Anthropometric assessment of adolescents $(n=279)$

\begin{tabular}{|llll|}
\hline Overweight & Frequency $(\mathbf{N})$ & Percentage $(\%)$ & $95 \% \mathrm{Cl}$ \\
\hline Yes & 26 & 9.32 & $6.40-13.36$ \\
\hline No & 253 & 90.68 & $86.63-93.59$ \\
\hline
\end{tabular}

The mean BMI for age was computed as $19.72 \mathrm{~kg} / \mathrm{m}^{2}$ with minimum and maximum as $13.74 \mathrm{~kg} / \mathrm{m}^{2}$ and $36.14 \mathrm{~kg} / \mathrm{m}^{2}$ respectively. The Body Mass Index age score was computed for categorizing adolescents as overweight. Overall, 26 among 279 adolescents i.e. 9.32\% were found to be overweight (i.e. heavy for their age). (Table 3)

\section{Risk factors associated with overweight}

The independent variables were separately assessed with overweight using bivariate regression to assess risk factors associated with overweight. Finally, variables with significant relationships were further subjected to multivariate analysis in final model.

The bivariate analysis carried out independently with socio-demographic variables and overweight found p-value less than 0.25 for five variables out of total sixteen variables which are: the age of adolescents, their place of residence, birth order, mother's educational status, and father's employment. These variables with significant variables were further subjected to multivariate analysis by controlling for other variables. (Table 4) 
Table 4

Association between overweight and background characteristics

\begin{tabular}{|c|c|c|c|c|}
\hline \multirow[t]{2}{*}{ Variables } & \multicolumn{2}{|l|}{ Overweight } & \multicolumn{2}{|l|}{ Unadjusted analysis } \\
\hline & Yes (No, \%) & No (No, \%) & OR $(95 \% \mathrm{Cl})$ & $\mathrm{p}$ value \\
\hline Age (years) & & & $\mathrm{p}$ value $=0.022^{*}$ & \\
\hline 11-13 (Ref) & $9(21.95 \%)$ & 32 (78.05\%) & 1 & \\
\hline $14-16$ & $10(6.41 \%)$ & $146(93.59 \%)$ & $0.24(0.091-0.647)$ & $0.005^{\star}$ \\
\hline $17-19$ & $7(8.54 \%)$ & 75 (91.46\%) & $0.33(0.113-0.968)$ & $0.044^{*}$ \\
\hline Sex & & & $p$ value $=0.764$ & \\
\hline Male (Ref) & $12(9.92 \%)$ & $109(90.08 \%)$ & 1 & \\
\hline Female & $14(8.86 \%)$ & $144(91.14 \%)$ & $0.88(0.39-1.98)$ & 0.764 \\
\hline \multicolumn{3}{|c|}{ Place of Residence } & \multicolumn{2}{|l|}{$p$ value $=0.197$} \\
\hline Urban (Ref) & $25(10 \%)$ & 225 (90\%) & 1 & \\
\hline Rural & $1(3.45 \%)$ & $28(96.55 \%)$ & $0.32(0.041-2.464)$ & 0.275 \\
\hline \multicolumn{2}{|l|}{ Type of Family } & & \multicolumn{2}{|l|}{$p$ value $=0.978$} \\
\hline Nuclear (Ref) & $16(9.36 \%)$ & 155 (90.64\%) & 1 & \\
\hline Joint & $10(9.26 \%)$ & $98(90.74 \%)$ & $0.988(0.43-2.26)$ & 0.978 \\
\hline Birth Order & & & $\mathrm{p}$ value $=0.05$ & \\
\hline First (Ref) & $16(13.68 \%)$ & $101(86.32 \%)$ & 1 & \\
\hline Middle & $6(8.57 \%)$ & $64(91.43 \%)$ & $0.59(0.22-1.59)$ & 0.299 \\
\hline Last & $4(4.35 \%)$ & 88 (95.65\%) & $0.28(0.03-0.092)$ & $0.031 *$ \\
\hline
\end{tabular}

This finding showed the significant relationship between age of adolescents and overweight with middleaged adolescents (14-16 years) having $0.24(p=0.005)$ odds of being overweight than that of early adolescents. While for late adolescents aged 17-19 years the odds of being overweight is $0.33(p=$ 0.044 ) times compared to early adolescents while holding constant other variables. Similarly, the adolescents residing in urban areas were found to be more overweight as compared to rural adolescents. No significant association was found between religion, ethnicity and type of family of adolescents with their overweight status. The mother with university degree has $8.68(p=0.005)$ odds of being overweight as compared to illiterate mother. (Table 5) 
Table 5

Association between overweight and parental characteristics

\begin{tabular}{|c|c|c|c|c|}
\hline \multirow[t]{2}{*}{ Variables } & \multicolumn{2}{|l|}{ Overweight } & \multicolumn{2}{|l|}{ Unadjusted analysis } \\
\hline & Yes (No, \%) & No (No, \%) & OR $(95 \% \mathrm{Cl})$ & $P$ value \\
\hline \multicolumn{3}{|c|}{ Mothers Education Level } & \multicolumn{2}{|l|}{$p$ value $=0.0628$} \\
\hline No education (Ref) & $5(6.17 \%)$ & $76(93.83 \%)$ & 1 & \\
\hline Informal education & $3(6 \%)$ & $47(94 \%)$ & $0.97(0.22-4.24)$ & 0.986 \\
\hline Primary & $3(5.25 \%)$ & $45(93.75 \%)$ & $1.01(0.23-4.44)$ & 0.986 \\
\hline Secondary & $6(9.68 \%)$ & $56(90.32 \%)$ & $1.62(0.47-5.60)$ & 0.439 \\
\hline Higher secondary & $5(18.52 \%)$ & $22(81.48 \%)$ & $3.45(0.91-13.02)$ & 0.067 \\
\hline University & $4(36.36 \%)$ & $7(63.64 \%)$ & $8.68(1.88-39.94)$ & $0.005^{\star}$ \\
\hline \multicolumn{3}{|l|}{ Fathers employment } & \multicolumn{2}{|l|}{$p$ value $=0.074$} \\
\hline Agriculture (Ref) & $4(6.90 \%)$ & $54(93.10 \%)$ & 1 & \\
\hline Private job & $3(6.52 \%)$ & $43(93.48 \%)$ & $0.94(0.19-4.43)$ & 0.94 \\
\hline Business & $7(10.77 \%)$ & $58(89.23 \%)$ & $1.62(0.45-5.87)$ & 0.45 \\
\hline Foreign employment & $5(11.36 \%)$ & $39(88.64 \%)$ & $1.73(0.43-6.86)$ & 0.43 \\
\hline Others & $5(41.67 \%)$ & $7(58.33 \%)$ & $9.64(2.08-44.64)$ & $0.004^{*}$ \\
\hline \multicolumn{5}{|l|}{${ }^{*} \mathrm{p}<0.05 ; * * \mathrm{p}<0.01$} \\
\hline
\end{tabular}

The food habit of adolescents was analyzed for assessing its association with overweight among adolescents. Three variables such as skipping meals per week, type of skipped meals and consumption of green leafy vegetables per week were further analyzed using multivariate logistic regression to depict the independent effect of variables on overweight. (Table 6) 
Table 6

Association between overweight and food habits

\begin{tabular}{|c|c|c|c|c|}
\hline \multirow[t]{2}{*}{ Variables } & \multicolumn{2}{|l|}{ Overweight } & \multicolumn{2}{|l|}{ Unadjusted Analysis } \\
\hline & Yes (No, \%) & No (No, \%) & OR $(95 \% \mathrm{Cl})$ & $\mathrm{p}$ value \\
\hline \multicolumn{3}{|l|}{ Meal frequency per day } & \multicolumn{2}{|l|}{$p$ value $=0.98$} \\
\hline Less than 3 times (Ref) & $7(9.86 \%)$ & $64(90.14 \%)$ & 1 & \\
\hline Equals to 3 times & $13(9.03 \%)$ & $131(90.97 \%)$ & $0.96(0.54-1.73)$ & 0.91 \\
\hline More than 3 times & $6(9.83 \%)$ & $58(90.63 \%)$ & $0.10(0.32-0.36)$ & $0.00 *$ \\
\hline \multicolumn{3}{|l|}{ Skipping meal per week } & \multicolumn{2}{|l|}{$p$ value $=0.21$} \\
\hline Never (Ref) & $8(6.25 \%)$ & $120(93.75 \%)$ & 1 & \\
\hline $1-3$ times per week & $15(12.71 \%)$ & $103(87.29 \%)$ & $2.18(0.89-5.35)$ & 0.088 \\
\hline More than 3 times per week & $3(9.09 \%)$ & $30(90.91 \%)$ & $1.5(0.37-5.99)$ & 0.566 \\
\hline \multicolumn{3}{|l|}{ Type of skipped meal } & \multicolumn{2}{|l|}{$p$ value $=0.12$} \\
\hline Breakfast (Ref) & $5(14.71 \%)$ & $29(85.29 \%)$ & 1 & \\
\hline Lunch & $2(5.88 \%)$ & $32(94.12 \%)$ & $0.36(0.06-2.01)$ & 0.24 \\
\hline Day Snacks & $2(5.41 \%)$ & $35(94.59 \%)$ & $0.33(0.05-1.83)$ & 0.20 \\
\hline Dinner & $9(19.57 \%)$ & $37(80.43 \%)$ & $1.41(0.42-4.66)$ & 0.57 \\
\hline \multicolumn{3}{|c|}{ Consumption of green leafy vegetables } & \multicolumn{2}{|l|}{$p$ value $=0.16$} \\
\hline Never (Ref) & $1(8.33 \%)$ & $11(91.67 \%)$ & 1 & \\
\hline 1-3 times per week & $16(7.55 \%)$ & $196(92.45 \%)$ & $0.89(0.10-7.40)$ & 0.92 \\
\hline More than 3 times per week & $9(16.36 \%)$ & $46(83.6 \%)$ & $2.15(0.24-18.81)$ & 0.48 \\
\hline
\end{tabular}

The variables related to physical activity were independently analyzed for predicting its association with overweight. One out of five variables showed a p-value less than 0.25 so this was taken for final multivariate analysis. Sedentary behavior is defined as spending more than 6 hours per day in a sitting or reclining position was found to be associated with overweight. The adolescents spending more than 6 hours per day in a sitting position were found to have 2.08 odds to be overweight than their counterparts. However, the relationship was not statistically significant. (Table 7) 
Table 7

Association between overweight and physical activity

\begin{tabular}{|c|c|c|c|c|}
\hline \multirow[t]{2}{*}{ Variables } & \multicolumn{2}{|l|}{ Overweight } & \multicolumn{2}{|c|}{ Unadjusted analysis } \\
\hline & Yes (No, \%) & No (No, \%) & OR $(95 \% \mathrm{Cl})$ & $p$ value \\
\hline \multicolumn{3}{|c|}{ Vigorous activity } & \multicolumn{2}{|l|}{$p$ value $=0.95$} \\
\hline No (Ref) & $9(9.18 \%)$ & $17(9.39 \%)$ & 1 & \\
\hline Yes & 89 (90.82\%) & $164(90.61 \%)$ & $1.02(0.43-2.39)$ & 0.95 \\
\hline \multicolumn{3}{|c|}{ Moderate activity } & \multicolumn{2}{|l|}{$p$ value $=0.58$} \\
\hline No (Ref) & $6(7.79 \%)$ & $71(92.21 \%)$ & 1 & \\
\hline Yes & $20(9.90 \%)$ & $182(90.10 \%)$ & $1.30(0.50-3.37)$ & 0.58 \\
\hline \multicolumn{3}{|l|}{ LTPA } & \multicolumn{2}{|l|}{$p$ value $=0.64$} \\
\hline No LTPA (Ref) & 15 (10.07\%) & 134 (89.93\%) & 1 & \\
\hline LTPA & $11(8.46 \%)$ & 119 (91.54\%) & $0.82(0.36-1.86)$ & 0.64 \\
\hline \multicolumn{3}{|c|}{ Sitting Hours per day } & \multicolumn{2}{|l|}{$p$ value $=0.07$} \\
\hline$<6$ hrs (Ref) & $10(6.54 \%)$ & $143(93.46 \%)$ & 1 & \\
\hline$>6 \mathrm{hrs}$ & $16(12.70 \%)$ & $110(87.30 \%)$ & $2.08(0.90-4.76)$ & 0.08 \\
\hline \multicolumn{3}{|l|}{ Screen time } & \multicolumn{2}{|l|}{$p$ value $=0.6$} \\
\hline <2hrs (Ref) & $15(8.72 \%)$ & 157 (91.28\%) & 1 & \\
\hline$>2 \mathrm{hrs}$ & $11(10.28 \%)$ & 96 (89.72\%) & $1.19(0.52-2.71)$ & 0.66 \\
\hline
\end{tabular}

Finally, the socio-demographics, food habits, and physical activity were analyzed in final model for identifying the major factors associated with overweight. This analysis showed that skipping dinner is statistically associated with overweight which means this variable has an independent effect on overweight while controlling for other variables. In this final model middle and later aged adolescents were found to have 0.27 and 0.66 odds of getting overweight compared to earlier adolescents keeping other variables constant. In addition to this, urban adolescents were found to be more overweight than their counterparts while controlling for other variables. Similarly, mothers educated up to higher secondary and university level were found to have 5.73 and 0.80 odds of getting overweight adolescents respectively. However, these results were not found to be statistically significant. (Table 8 ) 
Table 8

Factors associated with overweight

\begin{tabular}{|c|c|c|c|c|}
\hline \multirow[t]{2}{*}{ Characteristics } & \multicolumn{2}{|l|}{ Unadjusted analysis } & \multicolumn{2}{|l|}{ Adjusted analysis } \\
\hline & OR $(95 \% \mathrm{Cl})$ & p value & AOR (95\% Cl) & $\mathrm{p}$ value \\
\hline \multicolumn{3}{|c|}{ Age of respondents $\left(p\right.$ value $\left.=0.022^{\star}\right)$} & \multicolumn{2}{|c|}{ Final model $(p$ value $=0.28)$} \\
\hline $11-13$ (Ref) & 1 & & 1 & \\
\hline $14-16$ & $0.24(0.091-0.647)$ & 0.005 & $0.27(0.028-2.67)$ & 0.26 \\
\hline $17-19$ & $0.33(0.113-0.968)$ & 0.044 & $0.66(0.068-6.44)$ & 0.72 \\
\hline \multicolumn{5}{|c|}{ Place of Residence $(p$ value $=0.197)$} \\
\hline Urban (Ref) & 1 & & 1 & \\
\hline Rural & $0.32(0.041-2.464)$ & 0.275 & $0.33(0.030-3.71)$ & 0.37 \\
\hline \multicolumn{5}{|c|}{ Birth Order $(p$ value $=0.05)$} \\
\hline First (Ref) & 1 & & 1 & \\
\hline Second & $0.59(0.22-1.59)$ & 0.299 & $0.13(0.011-1.61)$ & 0.11 \\
\hline Last & $0.28(0.03-0.092)$ & 0.031 & $0.19(0.026-1.34)$ & 0.026 \\
\hline \multicolumn{5}{|c|}{ Mother's Educational Level $(p$ value $=0.06)$} \\
\hline No education (Ref) & 1 & & 1 & \\
\hline Informal education & $0.97(0.22-4.24)$ & 0.986 & $0.44(0.03-5.88)$ & 0.53 \\
\hline Primary & $1.01(0.23-4.44)$ & 0.986 & $0.27(0.018-4.15)$ & 0.35 \\
\hline Secondary & $1.62(0.47-5.60)$ & 0.439 & $0.70(0.068-7.14)$ & 0.76 \\
\hline Higher secondary & $3.45(0.91-13.02)$ & 0.067 & $5.73(0.41-79.64)$ & 0.19 \\
\hline University & $8.68(1.88-39.94)$ & 0.005 & $0.80(0.02-22.50)$ & 0.89 \\
\hline \multicolumn{5}{|c|}{ Father's Employment $(p$ value $=0.07)$} \\
\hline Agriculture (Ref) & 1 & & 1 & \\
\hline Government services & $1(0.17-5.80)$ & 1 & $0.45(0.021-9.45)$ & 0.60 \\
\hline Private job & $0.94(0.19-4.43)$ & 0.94 & $0.85(0.06-11.39)$ & 0.90 \\
\hline Business & $1.62(0.45-5.87)$ & 0.45 & $0.93(0.11-7.88)$ & 0.95 \\
\hline Foreign employment & $1.73(0.43-6.86)$ & 0.43 & $1.5(0.13-17.10)$ & 0.74 \\
\hline Others & $9.64(2.08-44.64)$ & 0.004 & $12.0(0.35-411.6)$ & 0.16 \\
\hline
\end{tabular}




\begin{tabular}{|c|c|c|c|c|}
\hline \multirow[t]{2}{*}{ Characteristics } & \multicolumn{2}{|l|}{ Unadjusted analysis } & \multicolumn{2}{|l|}{ Adjusted analysis } \\
\hline & OR $(95 \% \mathrm{Cl})$ & p value & AOR (95\% Cl) & $\mathrm{p}$ value \\
\hline Never & 1 & & & \\
\hline 1-3 times per week & $2.18(0.89-5.35)$ & 0.088 & 1 & \\
\hline More than 3 times per week & $1.5(0.37-5.99)$ & 0.566 & $0.52(0.080-3.46)$ & 0.50 \\
\hline \multicolumn{5}{|c|}{ Type of skipped meals ( $p$ value $=0.12$ ) } \\
\hline Breakfast (Ref) & 1 & & 1 & \\
\hline Lunch & $0.36(0.065-2.01)$ & 0.24 & $1.59(0.12-20.47)$ & 0.12 \\
\hline Day Snacks & $0.33(0.05-1.83)$ & 0.20 & $2.97(0.20-44.12)$ & 0.20 \\
\hline Dinner & $1.41(0.42-4.66)$ & 0.57 & $12.62(1.39-114.23)$ & $0.02 *$ \\
\hline \multicolumn{5}{|c|}{ Consumption of green leafy vegetables per week $(p$ value $=0.16)$} \\
\hline Never (Ref) & 1 & & 1 & \\
\hline $1-3$ times per week & $0.89(0.10-7.40)$ & 0.92 & $0.82(0.05-12.86)$ & 0.88 \\
\hline More than 3 times per week & $2.15(0.24-18.81)$ & 0.48 & $0.88(0.038-20.39)$ & 0.93 \\
\hline \multicolumn{5}{|c|}{ Amount of pocket money $(p$ value $=0.06)$} \\
\hline Up to NRs.50 (Ref) & 1 & & 1 & \\
\hline More than NRs. 50 & $0.220(0.028-1.68)$ & 0.14 & $0.19(0.012-3.098)$ & 0.24 \\
\hline \multicolumn{5}{|c|}{ Sedentary behavior $(p$ value $=0.07)$} \\
\hline$<6$ hrs (Ref) & 1 & & 1 & \\
\hline$>6 \mathrm{hrs}$ & $2.08(0.90-4.76)$ & 0.08 & $3.51(0.79-15.54)$ & 0.09 \\
\hline
\end{tabular}

Moreover, adolescents skipping meals more than three times per week were found to have 0.52 odds of being overweight compared to those whose who skip one to three times while controlling for other variables. However, the result is not significant statistically. In addition to this, adolescents skipping dinner were 12.62 times more likely to get overweight than those who skip breakfast with a significant result while controlling other variables. Adolescents having sedentary behavior (spending more than 6 hours a day in sitting/reclining position) were 3.51 times more likely to be overweight compared to their counterparts while controlling for other variables. (Table 8)

\section{Discussion}

This study was conducted to assess the prevalence of and risk factors associated with overweight among adolescents. The overall prevalence of overweight was obtained as $9.34 \%$ which is approximately 
similar to findings from other studies done in urban areas in Nepal. The current finding is similar to a study done in Kaski district which reported $8.1 \%$ prevalence of overweight and obesity among school adolescents with $5.8 \%$ and $2.3 \%$ prevalence of overweight and obesity respectively. ${ }^{13}$ However, this finding is slightly lower than another study done among urban school adolescents in Lalitpur municipality which reported prevalence of overweight as $12.2 \%$ (95\% Cl 8.9 to 15.5$){ }^{10}$ which might be due to variations in study sites as Hetauda is still considered as periphery in comparison to Kathmandu valley. Similarly, this prevalence is higher as compared to another study done in Kaski district which stated overweight prevalence as 3.3\%. ${ }^{14}$ This finding stands in contrast with Adolescent Nutrition Survey, 2014 which found only $1 \%$ of adolescent as overweight. ${ }^{11}$

Also, this study is supported by various other studies done in South Asian countries such as India, Pakistan and Bangladesh. The study done in Pakistan in 2012 reported prevalence of overweight as 8\% among adolescents which is almost similar in this study context. ${ }^{15}$ Similarly, two cross-sectional studies done in Bengal and Belgaum city of India found $6.75 \%{ }^{16}$ and $12 \%{ }^{17}$. This difference might be due to larger economy, wealthier people and adoption of a sedentary lifestyle. This unequal distribution in the prevalence of overweight among school adolescents might be due to variation in adopting a sedentary lifestyle in different study settings.

The present study assessed the risk factors associated with overweight among adolescents. Sex and type of school found no significant association with overweight. In contrast to this, a study done in Lalitpur city found the significant relationship of overweight with adolescents being male and studying in private school ${ }^{10}$ which might be due to least variation between types of school in study area as compared to urban areas. Similarly, the insignificant relationship of age, ethnicity, family type, and mothers' occupation with overweight depicted in that study are also comparable to current study. ${ }^{13}$

Another study found consumption of fruits and vegetables four times or less per week associated with overweight ${ }^{10}$ which is comparable to current study findings. Furthermore, another cross-sectional study done among adolescents in Kaski district reported having meals more than three times per day $(p<0.001$, $O R=14.06)$ and consuming vegetables more than three times per week $(p<0.001, O R=2.74)$ as an associated factor for overweight ${ }^{13}$ which contradicts with current findings depicting no significant association of meal frequency and consumption of vegetables with overweight. The association of vegetable consumption for more than three times per week is comparable with the same study as adolescents consuming green leafy vegetables more than three times per week had 0.82 lesser odds of being overweight compared to those who never consumed. This might be due to over or under-reporting of adolescents as food consumption pattern was assessed by using a frequency-based questionnaire which can pose a threat of recall bias. This variation might also be due to variation in availability and accessibility of foods in study site, being the junction of foothills and Terai region.

Another study identified adolescents performing a vigorous activity and involving in passive activities during leisure as associated factors for overweight. ${ }^{13}$ In contrast to this, present study did not find a 
significant association of overweight with vigorous physical activity. This study finding found an association between overweight and sedentary behavior of participants i.e. spending more than 6 hours a day in a sitting position $(p=0.09, O R=3.51)$. Similar findings have been obtained in a case-control study done in India which depicted engagement in sedentary behavior for more than 4 hours a day $(O R=2, p=$ 0.02 ) as an independent risk factor for overweight. ${ }^{18}$ Similarly, this study also supports the finding of an insignificant association of overweight with sex of adolescents and physical activity which is similar as of current study.

This study has not found the significant association of overweight with their lifestyle habits as mentioned in literature which may be due to the cross-sectional nature of the study being unable to check association. Also, the lifestyle habits and nutrition-related information are difficult to capture and analyze in detail from a single-shot study. In addition to this, another reason might be due to the concern that overweight is determined by multiple factors so identifying a single independent risk factor might not give the best indicator.

The study was conducted using a cross-sectional study design which might have limited strength to explain the independent predictor for overweight among adolescents in a single shot. Likewise, change in lifestyle and overweight over time is difficult to measure. The study findings are completely based on selfreporting by the school adolescents and such findings are likely to suffer from over-or under-reporting and recall bias. Further, it is also not generalizable to the national level.

\section{Conclusions}

Overweight as an emerging issue often poses a double burden among the population. Adolescents are at the greatest risk of developing behavioral and metabolic risk factors related to different kinds of noncommunicable diseases. This study shows that nearly one out of ten adolescents is overweight.

Overweight was found to be associated with the age of adolescents, their place of residence, birth order, maternal education, and father's occupation. This study depicts that early-aged adolescents (11-13 years) are more overweight as compared to middle and late adolescents. In addition to this, skipping meals, type of skipped meals, consumption of green leafy vegetables and sedentary behavior has been observed as lifestyle-related predictors for overweight. However, in the final model skipping dinner was a single variable found to be statistically significant. These findings necessitate the designing of appropriate interventions targeting certain groups with specific programs. Many habits of later life begin in adolescence. So, understanding the current situation of consistently prevalent under nutrition and rising over nutrition concerned one need to emphasize the issue and consider it as a priority issue.

\section{Abbreviations}

PPS: Probability Proportionate to Size; SRS: Simple Random Sampling; WHO: World Health Organization; Cl: Confidence Interval; OR: Odds Ratio; AOR: Adjusted Odds Ratio; UNICEF: United Nations Children's Fund; BMI: Body Mass Index

Page 15/18 


\section{Declarations}

\section{Ethics approval and consent to participate}

This study received ethical approval from Institutional Review Committee (IRC) of Patan Academy of Health Sciences (PAHS). All the participants were fully informed regarding study objectives and written informed consent was obtained from participants and for those who were below 16 years, written informed consent was taken from parents or guardians. Confidentiality of the data was maintained to the full extent. All data was stored in password protected computer database which was accessible only to the researcher team. All methods were carried out in accordance with relevant guidelines and regulations.

\section{Consent for publication}

Not applicable.

\section{Availability of data and materials}

The datasets used and analyzed in this study are available from the corresponding author (Ms. Elina Khatri) on reasonable request.

\section{Competing interests}

The authors have declared that no competing interests exist.

\section{Funding}

None

\section{Authors' contributions}

EK, KPB, RKY, SB and SP: research conceptualization. EK, KBP, SP and RKY: supervised the data collection and writing-original draft. EK, SB and RKY: formal analysis. EK, RKY, SB and SP: writing review and editing. All authors read and approved the final manuscript.

\section{Acknowledgements}

We would like to thanks all the research participants who provided their valuable time. We would also acknowledge School of Public Health, Patan Academy of Health Sciences (PAHS), for providing the environment and platform to carry out the research.

\section{Author details}

${ }^{1}$ MPH Scholar, School of Public Health, Patan Academy of Health Sciences, Lalitpur, Nepal 
${ }^{2}$ Research Officer, Nepal Health Research Council (NHRC), Ramshahpath, Kathmandu

${ }^{3}$ Birat Nepal Medical Trust Nepal, Kathmandu, Nepal

${ }^{4}$ Research Associate, Health Research Together Initiative (HeaRT: Initiative), Kathmandu

${ }^{5}$ Provincial Health Training Centre, Gandaki Province, Pokhara

${ }^{6}$ Professor, School of Public Health, Patan Academy of Health Sciences, Lalitpur, Nepal

\section{References}

1. World Health Organization. [cited 2019 Mar 11]. Available from: https://www.who.int/newsroom/fact-sheets/detail/obesity-and-overweight

2. Hills AP, Ranasinghe P, Misra A, Jayawardena R, Wijayabandara M. Nutrition Transition and Obesity Among Teenagers and Young Adults in South Asia. Curr Diabetes Rev. 2016;13(5).

3. Shakya T, Shakya N, Sharma S. Overweight And Obesity Among Early Adolescents FromGovernment And Private Schools Of Dharan, Nepal: A Comparative Study. Eur J Pharm Med Res. 2017;4(6):3159.

4. Adolescent Nutrition at a glance. World Bank Heal. 2003;(June). Available from: http://web.worldbank.org/archive/website01213/WEB/IMAGES/AAGADOLN.PDF

5. Seidell JC, Halberstadt J. The global burden of obesity and the challenges of prevention. Ann Nutr Metab. 2015;66(suppl 2):7-12. Available from: https://www.karger.com/Article/Pdf/375143

6. Delisle H, Chandra-Mouli V, Benoist B. Should adolescents be specifically targeted for nutrition in developing countries? To address which problems, and how? In 1998. p. 2-38.

7. Mazidi M, Banach M, Kengne AP. Prevalence of childhood and adolescent overweight and obesity in Asian countries: A systematic review and meta-analysis. Arch Med Sci. 2018;14(6):1185-203.

8. Bhurosy T, Jeewon R. Overweight and obesity epidemic in developing countries: A problem with diet, physical activity, or socioeconomic status? Sci World J. 2014;2014.

9. Harris KM, King RB, Gordon-larsen P. Healthy Habits Among Adolescents: Sleep, Exercise, Diet, and Body Image Bureau of Labor Statistics Conference Center, Washington, D. C. Results presented are preliminary. We are grateful to the National Institute of Child Health and Human Develop. 2003.

10. Piryani S, Baral KP, Pradhan B, Poudyal AK, Piryani RM. Overweight and its associated risk factors among urban school adolescents in Nepal: a cross-sectional study. BMJ Open. 2016;6(5):e010335.

11. Nepal Health Research Council Ministry of Health and Population. Adolescent Nutrition Survey in Nepal. 2014. Available from: http://nhrc.gov.np/wp-content/uploads/2017/07/latest-final-nutritionbook.pdf

12. Acharya AK, Paudel DMP, Wasti PC, Sharma RD, Dhital S. Status Report on Food and Nutrition Security in Nepal. 2018. 
13. Acharya B, Chauhan HS, Thapa SB, Kaphle HP, Malla D. Prevalence and socio-demographic factors associated with overweight and obesity among adolescents in Kaski district, Nepal. Indian J Community Heal. 2015;26(April 2015):118-22.

14. Prevalence and Knowledge on Obesity Among School Going Adolescents of Kaski, Nepal. J Nepal Pediatr Soc. 2018;38(2):63-8.

15. Ahmed J, Laghari A, Naseer M, Mehraj V. Prevalence of and factors associated with obesity among Pakistani schoolchildren: a school-based, cross-sectional study. East Mediterr Journal. 2013;19(3).

16. Bengal W, Bengal W. Overweight and Obesity among Urban Bengalee Early Adolescent School Girls of Overweight and Obesity among Urban. Iran J Pediatr. 2015;23(April 2013):237-46.

17. Gurung TR, VI NG. Overweight and Obesity among the Adolescent School Students in Belgaum City. J Nepal Med Assoc. 2014;52(9):791-5.

18. Bhuiyan MU, Zaman S, Ahmed T. Risk factors associated with overweight and obesity among urban school children and adolescents in Bangladesh: a case-control study. BMC Pediatr. 2013;13(72). 